\title{
O CURRÍCULO DA ÁREA DE CIÊNCIAS E A CONSTRUÇÃO DE UMA PEDAGOGIA INTERCULTURAL: A FORMAÇÃO DA EDUCADORES INDÍGENAS NA UNIVERSIDADE FEDERAL DE MINAS GERAIS (UFMG)
}

\author{
THE SCIENCE AREA CURRICULUM AND THE \\ CONSTRUCTION OF AN INTERCULTURAL PEDAGOGY: \\ THE FORMATION OF INDIGENOUS EDUCATORS AT THE \\ FEDERAL UNIVERSITY OF MINAS GERAIS (UFMG)
}

\author{
Marina de Lima Tavares* \\ Juarez Melgaço Valadares* \\ Célio da Silveira Júnior ${ }^{* \star}$
}

\begin{abstract}
RESUMO: Nesse trabalho apresentamos experiências curriculares vividas no Curso de Formação Intercultural para Educadores Indígenas (FIEI) da Universidade Federal de Minas Gerais (UFMG), área de Ciências da Vida e da Natureza (CVN), e nossa busca por compreender as interações entre os saberes tradicionais dos povos indígenas e o conhecimento científico em sala de aula. Para Aikenhead (2009) a educação científica nas aulas de ciências pode ser compreendida em termos do cruzamento de fronteiras culturais, a partir das experiências vividas pelos estudantes dentro e fora de sala de aula. Consideramos que a diversidade étnica presente em nossas salas de aula serve de âncora para uma pedagogia intercultural: a integração de grupos culturais distintos em espaço de reconhecimento e intercâmbio recíproco. A equipe de professores da habilitação CVN tem trabalhado os conteúdos de Física, Química e Biologia integrados por eixos temáticos, como instrumentos articuladores tanto das disciplinas entre si quanto na abertura do currículo para questões vivenciadas pelos professores indígenas em suas escolas. Aqui refletimos sobre os significados atribuídos a partir de leituras, discussões que fazemos em equipe e das avaliações dos alunos sobre os Módulos de aula. Pretendemos, sobretudo, a partir
\end{abstract}

\footnotetext{
Doutorado em Educação pela Universidade Federal de Minas Gerais (UFMG), com estágio de pós-doutorado pela Ohio State University (EUA). Professora adjunta da UFMG, atuando junto aos cursos de Ciências Biológicas, Formação Intercultural de Educadores Indígena (FIEI) e Licenciatura para o campo (LeCampo). Realiza pesquisas na área de educação em Ciências e Biologia, com enfoque nos seguintes temas: argumentação; discurso, diversidade, ensino e aprendizagem de ciências. Contato: marina_tavares@hotmail.com

* Doutorado em Educação pela Universidade de São Paulo (USP), com estágio de pósdoutorado pela Universidade Federal do Rio Grande do Norte (UFRN). Professor adjunto da Universidade Federal de Minas Gerais (UFMG). Temas de pesquisa: ensino de ciências, interculturalidade e formação docente e formação de professores indígenas. Contato: juarezm@ufmg.br

*** Doutorado em Educação pela Universidade Federal de Minas Gerais (UFMG). Atua junto aos cursos de Química, Formação Intercultural para Educadores Indígenas (FIEI) e Licenciatura do Campo (LeCampo) da UFMG. Pesquisador do Grupo de Pesquisa Educação, Interculturalidade e Formação Docente da UFMG. Contato: celio@fae.ufmg.br
} 
desta reflexão, subsidiar a construção de currículos e práticas inovadoras nas escolas indígenas, sempre permeadas pelo diálogo intercultural entre os saberes tradicionais dessas comunidades e o conhecimento científico acumulado historicamente. Questionamos: É possível pensar numa pedagogia da interculturalidade, ancorada em um projeto social que tenha como eixo norteador uma solidariedade emancipadora?

Palavras-chave: Pedagogia intercultural; Ensino de ciências; Organização do currículo.

ABSTRACT: In this work we present curricular experiences lived at the Intercutural Undergraduate Program for Indigenous Educators in the modality of Life Sciences and Nature of the Federal University of Minas Gerais (UFMG), and our search for understanding the interactions between traditional knowledge of indigenous peoples and scientific knowledge in the classroom. For Aikenhead (2009) science education in science classes can be understood in terms of crossing cultural boundaries, from the experiences lived by students inside and outside the classroom. We consider that the ethnic diversity present in our classrooms serves as an anchor for an intercultural pedagogy: the integration of distinct cultural groups into a space of reciprocal recognition and exchange. The teaching team of CVN has worked on the contents of Physics, Chemistry and Biology, integrated by thematic axes, as articulating instruments of the disciplines between them as well as in the opening of the curriculum for questions experienced by indigenous teachers in their schools. Here we reflect on the meanings attributed from readings, discussions we make in the team, and from student assessments of Classroom Modules. We intend, above all, from this reflection, to subsidize the construction of curricula and innovative practices in indigenous schools, always permeated by the intercultural dialogue between the traditional knowledge of these communities and the historically accumulated scientific knowledge. We question: Is it possible to think of a pedagogy of interculturality, anchored in a social project whose guiding principle is emancipatory solidarity?

Keywords: Intercultural pedagogy; Science teaching; Curriculum organization.

\section{INTRODUÇÃO}

Mudanças significativas ocorreram na educação desde o fim da década de 1980, principalmente com a Promulgação da Constituição Federal, em 1988, e com a entrada em vigor da Lei de Diretrizes e Bases da Educação, em 1996.

Em seus textos e nos vários desdobramentos específicos, esses documentos reconheceram, amplamente, os direitos sociais. Essas legislações representaram avanços significativos no campo educacional, ao trazerem para o debate questões defendidas pelos movimentos sociais: de um lado, a questão da democratização mediante a promoção da descentralização, da autonomia e da flexibilidade. De outro, a necessidade de se construir uma 
escola menos discriminatória, que contemple culturas diversas, e desenvolva as várias dimensões formadoras do fazer humano (ARROYO, 2000; ARROYO, 2004). Deparamos, atualmente, com a incorporação de parcela da sociedade tradicionalmente excluída da educação, bem como saberes, experiências e culturas não valorizadas anteriormente. Questões silenciadas pelos mecanismos excludentes da tradição escolar e da nossa herança social são debatidas e questionadas. Muitos docentes acreditam que a pluralidade cultural levaria a situações de conflitos que tornariam pouco operativo qualquer desenho curricular para uma turma ou escola.

Compreender a chegada desses alunos como um corte epistemológico implica perceber que carregam trajetórias de vida marcadas pela etnia, pelo gênero, pela classe social, com todo um sentido próprio do fazer humano. E esses "novos alunos" que chegam abrem caminhos para repensarmos a criação de um ambiente escolar menos hostil, para que o diálogo entre as diferenças seja efetivado. De fato, perceber esses alunos sugere uma revisão dos currículos oficiais, das formas de organização escolar; e aponta para uma radicalização, tal como proposto por Paulo Freire (1982), dos princípios éticos de igualdade, dignidade e emancipação. A chegada desses alunos traz consigo a demanda pela aceitação do outro e o seu reconhecimento como diferente, em sua inerente dignidade (GONZALO, ORTEGA, 1998).

Assim outros mapas, práticas e discursos são criados, mesmo que, às vezes, dispersos, ocultos, silenciados; discursos questionadores das mesmas coisas - domínio, produção e trabalho - mas a partir de outro olhar - as brechas, o consumo e o prazer (MARTIN-BARBERO, 2006). Sob esses outros olhares, a desumanização é distorção, e não vocação histórica; por um lado, é denúncia de uma adesão a uma estrutura impessoal, alienante, e, por outro, anúncio de outras possibilidades (FREIRE, 1982). Nos dizeres de Maria Eduarda Moniz Santos (2005), trata-se da construção de uma educação em/pela/para a cidadania, que coloque como linhas de força a diversidade, a liberdade, a solidariedade e a democratização do conhecimento, consolidandose como uma visão de educação em que as representações sobre o papel da ciência não seja um obstáculo epistemológico para a construção de outros 
saberes. Indagamos: do que falamos quando sustentamos que a escola deve educar para a interculturalidade e para a solidariedade?

O Curso de Formação Intercultural para Educadores Indígenas (FIEI), da Faculdade de Educação da Universidade Federal de Minas Gerais (FAE/UFMG) busca, sobretudo, subsidiar a construção de currículos e práticas inovadoras nas escolas indígenas, sempre permeadas pelo diálogo intercultural entre os saberes tradicionais dessas comunidades e o conhecimento científico acumulado historicamente, ou seja, a interculturalidade é a componente característica de um modelo pedagógico para esse Curso e para o trabalho docente indígena em suas escolas.

É nesse contexto que vamos refletir sobre nossas experiências na área de Ciências da Vida e da Natureza (CVN) deste curso. Ao entrarem na universidade, os estudantes indígenas fazem com que as questões relacionadas à suas lutas e interesses passem a ocupar o espaço público e fazer parte do cenário político de nossa sociedade. Desta forma, criam um espaço para que a universidade possa, efetivamente, comprometer-se com a luta contra a desigualdade neste país, que não se apresenta apenas sob a forma de desigualdade econômica, mas como exclusão social e cultural. Neste sentido, a aprovação e implantação do FIEI/REUNI constitui hoje um marco dentro da UFMG, abrindo a possibilidade de um diálogo intercultural entre os saberes acadêmicos presentes na cultura da universidade e os saberes tradicionais indígenas, presente na cultura de estudantes e lideranças indígenas que participam do curso.

Este trabalho tem como objetivo contribuir para uma reelaboração de atividades didáticas numa perspectiva intercultural, permitindo ao docente trabalhar em uma zona fronteiriça entre as culturas, transformando as salas de aula em um território para o encontro, o intercâmbio, o conflito e a negociação. É possível pensar numa pedagogia da interculturalidade, ancorada em um projeto social que tenha como eixo norteador uma solidariedade emancipadora? 


\section{A ESTRUTURA CURRICULAR DO FIEI}

O currículo do curso FIEl se agrupa em três núcleos: o Núcleo de Formação Específica, o de Formação em Ciências da Educação e o Núcleo de Formação Integradora que engloba os componentes: Estágio Supervisionado, Prática de Ensino, os Laboratórios Interculturais e os Projetos de Pesquisa. Por sua vez, cada habilitação tem uma duração de quatro anos totalizando oito períodos de Módulo e oito períodos de Intermódulo.

O Módulo se realiza na UFMG, duas vezes por ano, quando os alunos indígenas passam em torno de cinco semanas em atividades presenciais com os professores; o Módulo sempre inclui um Seminário Temático, organizado pelas habilitações, sobre temas e questões que envolvem o cotidiano de cada povo tanto no Brasil quanto no exterior, com palestras dadas pelos chamados sábios indígenas.

O Intermódulo acontece nas áreas de origem dos estudantes, nos meses intermediários aos do Módulo. Nesse período, os alunos desenvolvem atividades de estudo, pesquisa e produção de material didático. Essas propostas de trabalho são orientadas no sentido de formar o professorpesquisador, criando a possibilidade de que esse projeto, além de contribuir diretamente para a construção de uma escola que possa responder à demanda imediata de escolarização dos povos indígenas, possa também atender à necessidade de se construir espaços de pesquisa e produção de experiências inovadoras relativas à escolas nas aldeias.

Acreditamos que trabalhar nessa perspectiva implica em constantes interrogações dos sujeitos envolvidos nas suas práticas culturais - inclusive escolares - possibilitando a construção de um currículo de formação de professores, assim como dos currículos da escola fundamental indígena, baseada em um movimento da periferia para o centro, buscando sempre 0 diálogo no contexto da diversidade e das diferenças.

Nesse contexto, como avaliar a proposta curricular da habilitação CVN, em prática desde 2011 ? 


\section{A HABILITAÇÃO EM CIÊNCIAS DA VIDA E DA NATUREZA (CVN)}

O Curso regular de Formação Intercultural de Educadores Indígenas teve sua primeira turma com habilitação em CVN no ano de 2011. Este apresenta os seguintes princípios norteadores: contextualização dos processos formativos; a relação com os territórios e com as escolas indígenas; os vínculos com os projetos sociais das comunidades locais; a atenção à diversidade e o diálogo intercultural; por fim, o ensino pela pesquisa.

Ao desenvolver uma formação na área CVN, indagamo-nos sobre como devemos trabalhar nessa fronteira que, ao se voltar para os conhecimentos das grandes áreas da Ciência, deve simultaneamente recuperar e fortalecer os saberes tradicionais das culturas indígenas. Essa indagação ganha sentido, quando se constata que mesmo que, a partir da década de 1990, os pressupostos que orientavam o ensino de ciências tenham passado por mudanças e educadores e pesquisadores da área tenham começado a questionar a superioridade do conhecimento científico face ao conhecimento tradicional (EL HANI, SEPÚLVEDA, 2006), a educação científica tem o potencial de gerar um efeito desintegrador sobre outras formas de representação do mundo o que pode levar o conhecimento escolar a desprezar a cultura popular, considerando-a inferior (MORTIMER, 1998).

Na turma da habilitação CVN que ingressou em 2011, trabalhamos com alunos dos povos Xakriabá, que moram no norte de Minas Gerais e Pataxó de Minas Gerais e do Sul da Bahia. Partindo do princípio de que temos uma proposta de trabalhar numa perspectiva de diálogo intercultural nos parece essencial questionar como esses povos chegam à UFMG e que práticas pedagógicas e curriculares darão conta de seus processos formativos.

\section{REFERENCIAL TEÓRICO}

O ensino de ciências numa perspectiva intercultural

Nós, docentes da Área de Ciências da Vida e da Natureza do FIEl, valorizamos o conhecimento científico e o consideramos relevante para a 
sociedade, sem, no entanto, tratá-lo como o único tipo de conhecimento importante, nem o melhor conhecimento dentre os vários que circulam na sociedade. Segue-se aqui, a ideia de pluralismo epistemológico proposta por Cobern e Loving (2001), que evita o cientificismo, reconhecendo a variedade de formas de conhecimento, assim como as diferenças que eles apresentam entre si (EI-HANI, MORTIMER, 2007). Para Cobern e Loving (2001), o fato de o conhecimento científico ser exclusivo não confere à ciência qualquer privilégio com relação a outros domínios do conhecimento. A ciência seria assim, propriamente privilegiada dentro do seu domínio, pois é lá onde sua força reside.

Outro aspecto que fundamenta essa visão é a perspectiva intercultural de ensino, que pressupõe um conjunto de inter-relações no âmbito tanto individual como coletivo, uma abertura ao diálogo com o outro, sínteses quando é possível produzi-las e respeito a olhares diferenciados de conceber a realidade (CREPALDE, AGUIAR JÚNIOR, 2012).

Essa perspectiva intercultural aparece no contexto das pesquisas sobre o ensino de ciências, quando autores como Aikenhead (2009) e Mortimer (1996) tratam o ensino de ciências como uma introdução do estudante no universo de outra cultura. Segundo Aikenhead (2009) a visão que temos das coisas é construída pelo cruzamento de várias subculturas, a subcultura da ciência, da religião, da família, da escola, etc. Ele reconhece, nas aulas de ciências, a existência de vários grupos ou subgrupos que transitam cotidianamente por várias subculturas e considera que a educação científica nas aulas de ciências pode ser compreendida em termos do cruzamento de fronteiras culturais, a partir das experiências vividas pelos estudantes dentro e fora de sala de aula (AIKENHEAD, 2009).

Para Mortimer (1996), a aprendizagem de ciências também envolve um processo de "enculturação", em que os estudantes são inseridos numa nova forma de explicar e pensar o mundo natural, diferente das explicações do senso-comum. Tal enculturação envolve um processo de socialização das práticas da comunidade científica e de suas formas particulares de pensar e de ver o mundo (MORTIMER, 1996). 


\section{A interculturalidade como modelo pedagógico}

A perspectiva intercultural aparece também, nas discussões sobre as escolas indígenas e sobre os conhecimentos que circulam nesses espaços. A antropóloga Antonella Maria Imperatriz Tassinari (2001) defende uma abordagem da escola indígena enquanto "fronteira", que contempla além da possibilidade de diálogo entre conhecimentos distintos, a existência de interdições e incompreensões nesse diálogo. Nessa perspectiva, a escola indígena é considerada um espaço de interação e contato entre populações, onde há o fluxo de pessoal e conhecimento e onde as diferenças sociais são construídas. É considerada também, um espaço no qual ocorrem situações de interdição desse fluxo de conhecimentos, que inclui zonas de total desencontro as quais não se constituem em barreiras estáveis, mas funcionam também de forma dinâmica, fornecendo material que vem reforçar diferenças ou manter distinções étnicas (TASSINARI, 2001).

Essas discussões sobre perspectivas de educação intercultural são de grande relevância para as pesquisas relacionadas à formação de professores indígenas, visto que nesse processo formativo há, além de uma circulação de diferentes saberes e de diferentes atores (professores indígenas, professores universitários, bolsistas universitários) por diferentes espaços (universidades, aldeias e as escolas indígenas), uma série de situações de incompreensões e interdições, nas relações e nos discursos desses sujeitos.

Os povos indígenas chegam marcados pelos problemas sociais e políticos de suas regiões: questões ligadas à demarcação de terras, as lutas contra o agronegócio e as monoculturas, falta de água e saneamento básico, trabalho em lavouras, enfim, pelas condições precárias de vida. Aliado a essas questões, deparamos com a riqueza de suas práticas culturais, de seus rituais, de seus conhecimentos tradicionais, dentre outras. Dessa forma, colocam em questão os nossos códigos, nossos processos de identificação e pertencimento, e que exigem interações e saídas complexas, com novos desafios nas dimensões jurídicas, política, sociocultural e educativa. Eles não são o prolongamento de nós mesmos. 
Tal compreensão sugere, ainda, uma perspectiva intercultural da educação, onde o fortalecimento das identidades emerge enraizado nos movimentos sociais e políticos dos sujeitos e povos diversos. Daí a relevância de práticas educativas inovadoras, que recolhem esses saberes não no sentido de desintegrá-los, mas na trilha de novas possibilidades de integração em que nenhum deles se anule. Nesse sentido, o saber indígena não é mera oposição ao conhecimento científico, mas uma formulação específica da cultura e das vivências sociais, tão significativas quanto os saberes da Ciência. A proposta pedagógica do FIEI visa conferir outras lógicas de saberes utilizando como estratégia o diálogo entre diferentes sistemas de conhecimento e de culturas. Essa proposta de formação dos professores indígenas oferece um aporte importante tanto no que se refere ao reordenamento dos conteúdos disciplinares das escolas indígenas - ainda ancorado em uma concepção oficial de currículo - quanto ao problema da supremacia do saber produzido no espaço acadêmico em relação a outros conhecimentos.

Pensar na transformação da diversidade, aceitação e solidariedade em processos educativos transversais afetam tanto as disciplinas quanto a própria organização escolar. Para Gonzalo e Ortega (1998), tal caminho implica uma progressiva ruptura com certas pautas, hábitos e convenções relacionadas ao ambiente educativo: com o programa oficial, com o livro texto, com os calendários anuais, e com as interpretações arquetípicas aceitas pela comunidade científica.

Tais mudanças não são apenas difíceis de levar adiante pela sua complexidade, como também pela existência de resistências explícitas ou não. As relações de poder e o fato de haver fortes níveis hierárquicos na comunidade universitária, aliados a falsa dicotomia entre o conhecimento científico e o tradicional interferem nos nossos espaços relacionais favorecendo o surgimento de emoções que restringem a visão das pessoas, dificultam o desenvolvimento de projetos colaborativos, de novos conhecimentos e a aceitação de saberes oriundos de outras tradições. Assim, a relação se torna ainda mais ruidosa, pois é muito frequente supor-se que a forma de produção de conhecimento científico seja o apogeu de um processo de evolução das 
formas de produzir conhecimento na história da humanidade (VALADARES, PEREIRA, 2015).

Podemos considerar que as relações entre educação e pluralidade cultural têm se acentuado nas últimas décadas. Ao contrário de uma teoria que defende a integração de uma cultura a outra, isto é, o abandono forçado de uma determinada cultura cujas características se tornam inofensivas e folclóricas, atualmente certos grupos defendem a convivência e o reforço de distintas culturas. Essa diversidade étnica serve de âncora para uma pedagogia intercultural: a integração de grupos culturais distintos em espaço de reconhecimento e intercâmbio recíproco (GONZALO, ORTEGA, 1998).

Temos claro que cada um desses modelos se reproduz hoje nos espaços institucionais. Muitas vezes, a assimilação à cultura dominante e seus modelos de excelência capturam os alunos de determinados grupos étnicos devido ao valor positivo que transpassam e mesmo em alguns momentos sua aceitação torna-se necessária para evitar situações de exclusões de determinados alunos.

Essa tensão perpassa o tempo todo a nossa prática, muitas vezes ancorada em concepções disciplinares do currículo. Marlucy Paraíso (2010, p. 153) chama a nossa atenção quando escreve:

\begin{abstract}
Um currículo é um composto heterogêneo constituído por matérias díspares e de naturezas distintas; por saberes diversos e com capacidades variadas; por sentidos múltiplos e com inúmeras possibilidades. Um currículo está sempre cheio de ordenamentos, de linhas fixas, de corpos organizados, de identidades majoritárias. Porém um currículo também está sempre cheio de possibilidades de rompimento das 'linhas do ser', de contágios que podem nascer e se mover por caminhos insuspeitados; de construção de modos de vida que podem se desenvolver de formas particulares.
\end{abstract}

Nessa linha, procuramos, no FIEI, construir um currículo que permita diálogos com os modos de vida dos povos nele imersos. Um currículo onde a diversidade é vantagem acadêmica. Que reflexões nós professores fazemos sobre essas práticas? 


\section{UMA APROXIMAÇÃO DA NOSSA PRÁTICA DE ENSINO COM A PESQUISA}

Nosso olhar para a prática como docentes do FIEI se aproxima do olhar da pesquisa de natureza qualitativa, já que buscamos apreender os movimentos e a complexidade dos fenômenos sociais em seu contexto (LÜDKE, ANDRÉ, 1986). Nesse caminho, há uma maior aproximação entre pesquisador e objetos pesquisados. Os significados são atribuídos a partir de nossas leituras e das discussões que fazemos dos fatos levantados nas avaliações de cada Módulo: o que houve em cada disciplina relativamente aos conteúdos e/ou temas, em quais momentos os alunos participaram mais e/ou se envolveram menos. Enfim, quando se observou uma prática que poderíamos chamar de intercultural, ou mesmo quando a voz do aluno foi silenciada, ou, por algum motivo, interditada.

Temos hoje um banco de dados composto por diário de campo de professores e bolsistas, avaliações dos alunos sobre o curso, enfim, dados que podem ser utilizados pelas pessoas do grupo. Porém, o que tem norteado o trabalho de pesquisa refere-se ao planejamento e construção dos conteúdos em cada módulo, e como esses conteúdos e eixos temáticos são modificados pelas situações vivenciadas em sala de aula.

Como pano de fundo, interrogamos, como objeto de pesquisa, o que ocorre quando essa experiência de contato com uma cultura diversa questiona o sujeito na continuidade de si mesmo, na organização de suas identificações, no emprego de certos mecanismos de defesa, na coerência entre as suas formas de pensar e atuar, na confiança depositada em seus grupos de pertencimento, e na eficácia dos códigos comuns a todos aqueles que pertencem a um conjunto (KAËS, 2014). Construímos, sobretudo, alguns aspectos que são indicativos dessa pedagogia intercultural.

Porém, o que observar concretamente? Em Primeiro lugar, se há uma adequação inicial do planejamento às questões postas no território indígena. A preocupação em centrar as atividades em possíveis aspectos da vivência indígena mostra um caminho que é útil para a escola: implica partir dos conhecimentos que cada um deles já traz consigo sobre o tema a ser abordado. Inclusive, o tema e os problemas das escolas indígenas poderão se 
tornar o núcleo vertebral da formação docente, isto é, o eixo temático definido pelos professores se direciona para um currículo social e cultural que não procede do mundo acadêmico. Indagamos: Até que ponto nos preocupamos em escutar os grupos indígenas na formatação do planejamento da área CVN? Esse planejamento possui caráter globalizador, admite mais de uma leitura da realidade, e, além disso, integra um maior número de variáveis e interações de forma a dar conta da complexidade do real? São projetos interdisciplinares, que rompem com o caráter disciplinar do currículo?

Em segundo lugar, a pedagogia intercultural supõe sempre a aparição do conflito (GONZALO, ORTEGA, 1998), isto é, formula-se uma pedagogia cujo ponto inicial são os conflitos culturais, e para os quais são necessárias ações que transbordam os muros da escola na tentativa de resolvê-los. Esses conflitos podem ocorrer tanto em posicionamentos sobre situações sociais vivenciadas concretamente pelos grupos em contato, quanto em questões conceituais de determinada área de conhecimento em contexto de sala de aula. São esses conflitos vividos de forma construtiva? Esses conflitos propiciam uma mudança em nossa forma de compreender o conhecimento científico?

Além disso, um currículo cujas disciplinas se tornam espaços para a ação social, política e cultural referenda a construção de uma prática investigativa e de pesquisa da realidade dos povos indígenas e de suas escolas, bem como a construção didática da memória pessoal, do grupo e do território. Mais do que oferecer um arsenal de leituras críticas do contexto, a pesquisa como metodologia de ensino traz consequências para a prática docente: a indissociação método-conteúdo, isto é, os temas resultantes do encontro entre o conhecimento científico e dos saberes tradicionais são desenvolvidos por meio de práticas pedagógicas mais interacionistas (DELIZOICOV, ANGOTTI, PERNAMBUCO, 2002) Nesse caso, a pesquisa, como trajetória individual ou coletiva, é possibilidade de construções curriculares inovadoras, pois gera a possibilidade de respeito e tolerância pela cultura do outro; o que ensinar e o que aprender surgem dessas interações entre os diversos discursos que ocorrem em determinado espaço e tempo. Sobretudo, a física das armadilhas indígenas, o estudo das plantas medicinais, 
a influência da lua na vida cotidiana, a produção de farinha, os modelos explicativos, vão sendo pesquisados e incorporados ao currículo ao mesmo tempo. Perguntamos: nossas ações e atividades têm permitido um olhar e uma melhor compreensão da realidade dos povos indígenas.

Deparamos, sobretudo, com a pergunta: estamos construindo uma convivência dos grupos culturais distintos de maneira a promover intercâmbios e enriquecer a cultura de cada povo indígena?

As reflexões que serão apresentadas no próximo tópico se referem à experiência que tivemos com a primeira turma da habilitação CVN, que ingressou na UFMG no ano de 2011. Essa turma apresentava alunos das etnias Pataxó da Bahia e de Minas Gerais, além dos Xakriabá, de Minas Gerais.

\section{DISCUSSÃO DE ELEMENTOS DA EXPERIÊNCIA CURRICULAR DA HABILITAÇÃO CVN}

No início da Habilitação CVN, em 2011, a equipe de trabalho ${ }^{1}$ fez a opção de trabalhar um tema em comum para cada semestre letivo. No planejamento dos Módulos, o material didático de cada professor era pensado e discutido coletivamente entre os docentes e os bolsistas da habilitação. Procuramos garantir, de fato, a possibilidade do tema como elemento articulador tanto das disciplinas entre si quanto na criação de possíveis saídas para questões apontadas pelos alunos indígenas em seu cotidiano. Além disso, definiu-se que cada Módulo teria uma atividade coletiva fora dos muros da sala, tais como visita a museus, parques, cidades históricas, dentre outros. Esses espaços não formais de aprendizagens encontram enorme ressonância entre os educadores indígenas, acostumados a esse mesmo trabalho de exploração ambiental e pesquisa na comunidade em que vivem. Uma das visitas foi ao Espaço do Conhecimento da UFMG, onde os indígenas tiveram contato com Planetário. Vejamos a avaliação dos alunos sobre a visitação:

\footnotetext{
1 A equipe refere-se ao grupo de professores e bolsistas de mestrado e doutorado que compõem o grupo, além de pessoas que são convidadas para auxiliarem no debate e discussões em cada Módulo.
} 
Gostei muito. Teve várias coisas importantes [...] Nos fez lembrar de alguns artefatos que tem na nossa comunidade e que é importante fazer a conservação. Já é uma coisa que fazemos. Porque para nós é uma preciosidade da nossa cultura.

Outra aluna indígena relatou a "magia" que representou para ela a ida ao Planetário:

Durante a apresentação tive uma experiência muito rica, e relembrei das histórias que meus pais contavam quando eu era criança sobre os astros. [...] Pude observar que a lua é totalmente diferente do que eu imaginava. [...] Essa apresentação me fez recordar sobre as noites em que eu dormia a céu aberto com minha família, por causa do calor durante a noite. Enquanto o sono não chegava eu ficava observando as estrelas.

E esse mesmo sentimento, associado ao prazer de estudar esses conteúdos, foi registrado por outro aluno:

O Espaço TIM é um lugar de informação muito bom. Gostei muito quando eu cheguei. Senti estudando o passado e compreendendo o presente. Me surpreendeu muito quando vi os satélites no espaço e os foguetes entrando em órbita. Me senti eu próprio no espaço, uma sensação muito boa. É maravilhoso estudar o espaço, o universo e a criação da humanidade. Muito legal.

Quanto à carga horária dos Módulos, organizamos as duas primeiras aulas (8 horas) e as duas últimas (8 horas) de modo a serem coletivas, com a participação de todos os professores e bolsistas da habilitação CVN. Acreditamos que a presença de mais de um professor em sala estimula 0 debate e enriquece as ideias, pois aprofunda os temas em estudo, auxiliando os alunos observarem um fenômeno ou uma situação de maneira diversa. Além disso, nos módulos existem outros momentos coletivos que contam com a presença do coletivo: as aulas destinadas ao estágio obrigatório - junto com todas as habilitações; os seminários temáticos - que também agregam alunos, professores e bolsistas de todas as habilitações; e as aulas referentes aos percursos temáticos, que começam no primeiro módulo e os acompanham até a formulação dos trabalhos de conclusão de curso. 
No planejamento inicial para a turma que ingressou em 2011, que teve como eixo temático Energia e Meio-ambiente, a seleção dos conteúdos das disciplinas e a escolha de atividades extra-sala de aula foram pensadas em reuniões com todos os membros da equipe. A intenção era criar, desde o início, um grupo de professores e bolsistas comprometidos com as questões curriculares, e esse envolvimento, em nosso entendimento, somente ocorre se existe a possibilidade de um espaço aberto onde a fala de cada um pode ser reconhecida.

Esse eixo temático foi eleito para os dois primeiros módulos de aula, em que se trabalhou os diversos processos de transformação, conservação e degradação da energia em seus aspectos físicos, químicos, biológicos e socioambientais. O fato de se ter o mesmo tema para os dois módulos iniciais ocorreu em função da escuta da equipe de trabalho às questões realizadas pelos alunos. Primeiramente, a integração das disciplinas por meio de temas aproxima a educação científica da realidade cotidiana dos povos indígenas, e com isso amplia a participação em sala - Módulo - e nas pesquisas e produções realizadas no Intermódulo. Altera, sobretudo, a natureza da relação do aluno indígena com o conhecimento (científico ou tradicional), que passa de uma demanda passiva ou burocrática para patamares reflexivos e de participação ativa na busca dos saberes. Inferimos que há um salto na adesão dos alunos indígenas em direção a um patamar de maior envolvimento e participação no curso $\mathrm{FIEI}$, concomitantemente a uma maior reflexão tanto sobre os conhecimentos a fazer parte dos currículos quanto na dimensão metodológica a ser adotada nas suas escolas. Acreditamos que estes processos de subjetivação são auxiliados pela maior relação de parceira dos docentes entre si, o que influencia a receptividade ao saber do outro bem como as interações entre os próprios alunos e destes com o conhecimento. Vejamos algumas avaliações realizadas pelos/as aluno/as indígenas:

Comigo vai tudo ás mil maravilhas, passei a semana aqui na Faculdade estudando com o professor MJ sobre energia. Você sabe que energia é tudo aquilo capaz de dar movimento às coisas, e que existe diversas formas de energia, como eólica, cinética, nuclear, outras? Que elas fazem parte de nosso cotidiano e provocam impactos ambientais? 
Consideramos ainda, que essas trocas trazem consigo a necessidade de uma maior flexibilidade curricular, pois uma escuta atenta dos alunos indígenas se traduz em replanejamentos online. Como exemplo, o contato dos alunos com uma Casa de Energia (uma casa com simuladores para a determinação da conta de luz) durante uma visita à Estação Ecológica da UFMG, no primeiro Módulo levou a disciplina Energia e Ambiente a alterar completamente seus conteúdos em função das questões conceituais e sociais ligadas à produção, distribuição e ao consumo de energia elétrica, colocadas pelos alunos:

É com um prazer imenso que lhe escrevo essa carta para falar um pouco do que tenho aprendido na aula do Professor MJ. Aprendi algumas orientações sobre a forma de economizar energia em nossa casa, como calcular a energia usando a potência e o tempo durante o funcionamento de aparelhos utilizados.

As questões relacionadas ao conhecimento da produção de energia elétrica por uma usina hidrelétrica e o gasto de energia elétrica numa residência foram mencionadas por todos /as alunos/as como a grande aprendizagem do primeiro Módulo. Dessa forma, o currículo incorporou uma perspectiva de currículo com ênfase em Ciência, Tecnologia e Sociedade $(\mathrm{CTS})^{2}$, em função do envolvimento dos alunos em aprenderem como calcular o gasto de energia nos aparelhos eletrodomésticos. Compreender o gasto de energia de cada casa e de toda a aldeia movimentou a turma:

Essa experiência (consumo de energia) foi muito importante pelo fato de que nós (Povo Indígena) Xakriabá estamos passando por uma dificuldade muito grande, de nós fazermos uma grande economia, mas mesmo assim pagamos uma conta muito elevada [...] Aprendi muito mais sobre a Física.

\footnotetext{
2 De acordo com Santos e Mortimer (2002), currículos de ensino de ciências com ênfase em CTS - ciência, tecnologia e sociedade apresentam como objetivo central preparar os alunos para o exercício da cidadania e caracterizam-se por uma abordagem dos conteúdos científicos no seu contexto social. O objetivo central é desenvolver a alfabetização científica e tecnológica dos cidadãos, auxiliando o aluno a construir conhecimentos, habilidades e valores necessários para tomar decisões responsáveis sobre questões de ciência e tecnologia na sociedade e atuar na solução de tais questões.
} 
No terceiro Módulo, o tema foi Água, com o eixo centrado na disponibilidade, qualidade e tratamento desse recurso nos territórios dos alunos da turma. Trabalhou-se ainda, os parâmetros físico-químicos e biológicos de qualidade da água e sua relação com a saúde. Essa escolha pela equipe de professores e bolsistas foi feita levando-se em conta a relevância do tema apontada pelos próprios alunos. Assim, ao longo do Módulo, foram realizadas várias atividades nas disciplinas de biologia, física e química, que incluíram experimentos para discutir os estados físicos da água, visita à estação de tratamento de água do Parque Ecológico da Pampulha, visita ao Instituto de Biologia para discutir a análise da qualidade da água de rios com um pesquisador da área. Para o Intermódulo solicitamos uma pesquisa sobre a distribuição de água nas aldeias e a construção de mapas do território. Essa investigação levou os alunos a caminharem por suas aldeias, a entrevistarem pessoas mais velhas e a compreenderem melhor os modos de utilização da água, as dificuldades enfrentadas nas comunidades para a obtenção de água e os processos de captação utilizados, dentre eles o processo de captação da água da chuva. Esse trabalho proporcionou ainda, uma boa discussão sobre o uso da água no Brasil.

A escolha de temas geradores numa perspectiva interdisciplinar acarretou uma série de mudanças nas práticas docentes. Por exemplo, um aspecto que influenciou no planejamento do quarto Módulo foi uma questão colocada em sala por um aluno. Ao se discutir a existência de prótons, elétrons e nêutrons na constituição de um fio de cobre (condução de corrente elétrica) ele, após interessante debate, trouxe a pergunta: De que as coisas são constituídas? Os homens, as pedras, as plantas, os animais possuem a mesma essência, são constituídos pelas mesmas coisas?

Essa aula ocorreu no laboratório de Física, com a presença de dois professores da turma, na qual se discutia os aspectos descritivos de um circuito elétrico. Tratava-se de uma discussão sobre as formas de manifestação da energia, seus processos de transformação e conservação para que uma lâmpada incandescente se acendesse. A atividade foi pensada de forma a promover as interações dialógicas entre alunos e professores, e logo surgiu a 
pergunta feita por um aluno: "O que acontece dentro dos fios elétricos quando a Lâmpada acende?"

Essa indagação relacionava-se ao modelo microscópico da corrente elétrica, deixando de lado uma descrição macroscópica. Após a explicação pelo professor, o aluno perguntou se aqueles elementos - prótons, elétrons e nêutrons - constituíam também a mesa, as cadeiras, as pessoas, as plantas. Percebeu-se, naquele instante, que a "Sua problematização relacionava-se à constituição das coisas. Se prótons, elétrons e nêutrons constituíam um universal a fazer parte de todos os materiais". Enfim, ele construiu um outro sentido para o texto, direcionando a discussão para "qual seria, na visão docente, a essência das coisas"?

A resposta, nesse caso, poderia envolver questões e determinantes culturais. Ao perceberem o nível do que se propunha aquele debate, o docente respondeu de maneira rápida, e em forma de pergunta, a questão. Simultaneamente, começou a fazer perguntas ao aluno: o que ele achava daquele tema? O que ele responderia? E a turma, o que achava? Ao perceber certo agito e troca de olhares, o aluno renunciou ao debate. Notamos aqui que o diálogo intercultural não é exaustivo, e sim resultado de situações contextualizadas. Como interpretar a situação anterior? Inferimos que o professor, com receio de que o conteúdo pudesse desparecer, faz uma quantidade enorme de perguntas ao aluno, na busca de explicações ligadas à cultura indígena. Este, por sua vez, aparenta fazer um esforço significativo para formular as suas ideias de uma maneira inteligível para o docente, o que acabou gerando certa tensão. Quanto mais intensa a busca pela resposta nessa situação intercultural parece que ela a resposta) fica cada vez mais distante do professor. Neste momento este se vê diante do espelho (VALADARES, 2002), e vê uma imagem apagada como reflexão de sua própria concepção: a dificuldade de um diálogo intercultural em suas vicissitudes. Porém, é esse desconhecimento que nos levou à continuidade da pesquisa em situação intercultural no cotidiano da sala de aula.

Durante a reunião de avaliação do terceiro módulo, definimos que 0 tema do módulo seguinte seria a construção de modelos e suas relações com as teorias científicas. Talvez nesse momento o conflito intercultural estivesse 
colocado de modo explícito; não era apenas uma questão de concepções alternativas à visão da ciência, mas uma forma diferente de explicar a realidade.

Outro momento que vivenciamos de conflito intercultural foi durante 0 acompanhamento de uma monografia de fim de curso. Um aluno decidiu que seu trabalho deveria ter um retorno para toda a sua aldeia e, para tanto, definiu em recuperar o conhecimento dos mais velhos sobre as plantas medicinais indígenas. Porém, ao operar os dados da entrevista realizada com o pajé, percebeu que não apenas se tem a utilização de ervas como também todo um processo religioso que inclui dança, fumaças e cantos. Deparamos, aqui, com toda uma visão de medicina diferente da visão ocidental, na qual existe um tipo de acompanhamento espiritual que procura acalentar o doente. Em momentos como esse, a interculturalidade é explicitada nas diferentes formas de se pensar e viver que podem ser conflituosas ou complementares.

Consideramos que o currículo se desenvolve na prática e na constante reflexão sobre esta prática e procuramos, em nossa experiência com a equipe CVN, construir estratégias de aperfeiçoamento da proposta curricular na interação e integração entre a equipe de professores de diversas áreas de conhecimento e no desenvolvimento mais coletivo de nossas metodologias de ensino. Nessa caminhada, alguns avanços são nítidos. Mas também nos deparamos constantemente com novos desafios que nos demandam novas reflexões sobre a prática de formação de professores indígenas. Por exemplo, após um dos professores da CVN participar da discussão sobre a utilização do calendário socioambiental ${ }^{3}$ como mecanismo estruturador do currículo escolar

3 O curso possui um grupo de professores, de diversas áreas do conhecimento, que têm trabalhado com uma alternativa teórico-metodológica denominada de método intercultural indutivo, que pressupõe a pesquisa e utilização dos calendários de atividades socioecológicas (GASCHE, 2008) dos povos indígenas em questão; mais do que supor uma construção de conteúdos escolares, o método intercultural indutivo resgata o fazer e o saber-fazer presente nas práticas sociais, valorizando os conhecimentos e saberes presentes nessas atividades, e colocando questionamentos aos critérios que configuram a ciência moderna bem como tensões com os saberes acadêmicos. Não é a teoria científica que interroga a prática, e sim a teoria (científica) que dialoga com outra teoria (saberes presentes nas práticas). Para Gasche (2008), o ponto de partida são os conhecimentos tradicionais e as atividades realizadas antes, durante e depois de cada ação ou atividade. A partir dessa desconstrução, é escolhida uma temática que serve de "eixo gerador do tema". Todos os conteúdos da escola, independentemente do nível escolar, serão estudados e pesquisados a partir daqueles eixos. 
durante um Tempo Comunidade, gerou-se certa dissonância entre o tema comum definido pela equipe, a partir das necessidades das disciplinas e regido pelas pesquisas acadêmicas e o método indutivo presente no uso do calendário. Assim, deparamos com uma diferença significativa entre nossos eixos temáticos e os eixos geradores das escolas indígenas. Estaria a escola fazendo uma coisa e a habilitação CVN propondo outra?

Não consideramos que um Curso de Formação docente deva se ater apenas à realidade imediata da escola indígena, nem que exista uma realidade única de "escola indígena" já que são várias as realidades das escolas dos diversos povos indígenas brasileiros, considerando-se as especificidades culturais de cada povo e os desafios políticos que enfrentam suas terras e territórios. No entanto, consideramos relevante que, em cursos de formação de professores indígenas, haja uma busca constante da equipe docente por uma maior aproximação entre os saberes acadêmicos e os projetos, debates e ações dos alunos/professores indígenas no desenvolvimento de suas escolas e comunidades. De fato, em relação aos alunos Pataxó e Xakriabá da turma CVN, o calendário é discutido com todos os professores das escolas e das comunidades atendidas, ao passo que os temas transversais apenas nas disciplinas da área CVN, mesmo que com a participação intensa dos alunos.

A partir dessa constatação, no último Módulo os alunos das diversas aldeias apresentaram ao grupo docente do FIEI seus calendários, bem como os avanços e dificuldades de colocá-los em prática. Como contrapartida, apresentamos e discutimos junto ao grupo de alunos, os nossos projetos de pesquisa. A ideia é articularmos esses diferentes conhecimentos e demandas da escola, da pesquisa, das comunidades.

\section{ALGUMAS CONCLUSÕES SOBRE A CONSTRUÇÃO DO CURRÍCULO CVN}

Apresentamos nesse trabalho agenciamentos que ocorrem em sala de aula quando temos duas culturas presentes; a aparição de conflitos culturais, a construção de currículos mais próximos das vivências dos povos indígenas e atividades curriculares que ampliam a capacidade de tomada de decisões. Acreditamos que a área CVN tem feito uma organização do trabalho escolar 
pertinente ao que se espera desses encontros entre diferentes culturas. Procuramos apresentar nos exemplos de interações discutidos neste trabalho que a educação intercultural não é um conteúdo novo ou apenas uma estratégia metodológica, e sim posicionamentos nas diversas dimensões das vivências entre culturas diversas.

Na perspectiva da organização do currículo da área CVN do curso FIEI, temos como mola mestra a integração dos conteúdos por meio do desenvolvimento de eixos conceituais temáticos (Energia, Água, Modelos). Esses eixos podem ser modificados ou alterados à medida que o currículo é posto em prática e professores, bolsista e alunos interagem em sua construção. A escolha por esse modo de organizar o currículo é justificada pela tentativa de criar condições que permitam aos alunos articularem conhecimentos de áreas distintas das ciências com conhecimentos tradicionais indígenas, tanto ao longo dos módulos quanto durante as atividades de Intermódulo. O currículo constitui-se, desse modo, em um programa aberto, flexível e abrangente, que permite abordar temas de ciências adequando-os ao contexto, por meio de uma prática pedagógica marcada pela reflexão e participação dos alunos indígenas. É importante ressaltar a relevância das idas dos professores e bolsistas de pós-graduação para as áreas em que os alunos da turma vivem, durante o Intermódulo. Nessas idas, além de se realizar o acompanhamento dos trabalhos desenvolvidos pelos alunos indígenas também são acompanhadas atividades cotidianas desses alunos, sejam relacionadas ao seu dia a dia, às festas tradicionais, como casamentos, mas, principalmente, à organização e dinâmica de suas escolas. Esses momentos são essenciais para que a equipe docente do FIEI/CVN conheça na prática, as lutas e demandas das comunidades e etnias com as quais trabalha e que repense o seu currículo numa perspectiva de indissociação método-conteúdo.

Não temos dúvidas de que o $\mathrm{FIEl}$ se inscreve dentro de diretrizes políticas inovadoras tanto para as escolas indígenas e universidades quanto para as relações sociais existentes no país; numa sociedade ainda marcada por interesses econômicos distintos, o atendimento aos povos indígenas, no que se refere à educação, é parte de uma conquista de uma sociedade mais justa e humana. De forma geral, a nossa área aderiu de forma coletiva aos 
grandes desafios colocados pela atenção à diversidade, sobretudo nos seguintes aspectos: a quebra do mito da homogeneidade, possibilidade de currículos que permitem ajustes ao longo do tempo, construção de trabalhos colaborativos, uma relação de pesquisa sobre os trabalhos realizados.

De acordo com GASCHÉ (2008), não é possível existir um diálogo de saberes num sentido equilibrado, igualitário e simétrico em um sistema global no qual um tipo de sociedade - capitalista, liberal, individualista, materialista, monetarizada - domina sobre outros tipos de sociedade. O que pode ocorrer, por outro lado, é um processo de interaprendizagem entre os membros da sociedade dominante $\mathrm{e}$ as pessoas que são membros de sociedades tradicionais, sempre em situações concretas claramente definidas e assumidas, e nas quais as finalidades dos conhecimentos adquiridos estão claramente definidas e aceitas.

Gasché (2008) propõe assim que renunciemos à expressão diálogo de saberes, que não reflete o que ocorre na realidade e que falemos de interaprendizagem cultural que representa um desafio específico para cada um de nós como indivíduos - um desafio cujos objetivos sempre serão definidos no contexto de relações dominação/submissão.

Trabalhar o currículo nessa perspectiva implica na tentativa de engajar o aluno num processo de aprendizagem ancorado em situações-problema, mais complexas do que aquelas fragmentadas encontradas em alguns livros e sequências didáticas tradicionais. A educação não é algo trivial, pois implica criar condições para que as pessoas compreendam os problemas postos pelo avanço da civilização, não de maneira simplista, mas, sobretudo, reconhecendo a importância e a necessidade de manter sempre em pauta o diálogo entre a ética e a cultura.

Esperamos que o currículo, a partir do planejamento coletivo, produza novos sentidos para os sujeitos envolvidos, e seja capaz de propiciar outra mediação entre os conceitos científicos construídos historicamente e os problemas da vida contemporânea. Sobre essa articulação, ela gera encontros das lógicas disciplinares com a lógica do senso comum e dos conhecimentos tradicionais, bem como debates de valores. Sempre associada a questões de cidadania. 


\section{REFERÊNCIAS BIBLIOGRÁFICAS}

AIKENHEAD, G. S. Educação Científica para todos. Trad. Maria Teresa Oliveira. Lisboa: Edições Pedagogo, 2009.

ARROYO, M. G: Ofício de Mestre: imagens e auto-imagens. - Petrópolis. RJ: Vozes, 2000.

Imagens quebradas: trajetórias e tempos de alunos e mestres. Petrópolis, RJ: Vozes, 2004.

COBERN, W. W.; LOVING, C. C. Defining "science" in a multicultural world: Implications for science education. Science Education, v.85, p.50-67. 2001.

CREPALDE, R. S.; AGUIAR JÚNIOR, O. G. de. Da energia pensada à energia vivida: um diálogo intercultural com as ciências. $2012.165 \mathrm{f}$. Dissertação (Mestrado em Educação em Ciências) - Faculdade de Educação, Universidade Federal de Minas Gerais, Belo Horizonte, 2012.

DELIZOICOV, D.; ANGOTTI, J. P.; PERNAMBUCO, M. M. Ensino de ciências: fundamentos e métodos. São Paulo: Cortez, 2002. (Coleção Docência em formação).

EL-HANI, C. N.; MORTIMER, E. F. Multicultural education, pragmatism, and the goals of science teaching. Cultural Studies of Science Education, v.2, p.657 687, 2007.

EL-HANI, C.N; SEPÚLVEDA, C: Referenciais teóricos e subsídios metodológicos para a pesquisa sobre as relações entre educação científica e cultura. In: SANTOS; F.M.T; GRECA, I.M (Orgs): A pesquisa em ensino de ciências no Brasil e suas metodologias. - ljuí: Ed.Unijuí. Coleção Educação em Ciências, 2006.

FREIRE, P. Pedagogia do oprimido. 11ª Edição. Rio de Janeiro: Paz e Terra, 1982. $218 p$

GASCHE, J. ¿Qué son 'saberes' o 'conocimientos' indígenas, y qué hay que entender por 'diálogo'? In: $1^{\circ}$ Encuentro Amazónico de Experiencias:

Memorias e Diálogo de Saberes, Leticia, Colombia. 2008.

GONZALO, L.A.A; ORTEGA, P.S: De La Tolerancia a La Interculturalidade: un proceso educativo em torno a la diferencia. 1.ed. Madrid - Editora Anaya, 1998, 246p.

KAËS, R. As alianças inconscientes. São Paulo: Ideias \& Letras, 2014.

LÜDKE, M.; ANDRÉ, M.E.D.A. Pesquisa em educação: abordagens qualitativas. São Paulo: EPU/EDUSP, 1986. 
MARTIN-BARBERO, J: Dos meios às mediações: comunicação, cultura e hegemonia. Tradução de Ronald Polito \& Sérgio Alcides. 4. ed. - Rio de janeiro: editora UFRJ, 2006. 360p.

MORTIMER, E. F. Construtivismo, Mudança Conceitual e Ensino de Ciências: Para onde vamos? Investigações em Ensino de Ciências, v. 191, pp.20-39, 1996.

MORTIMER, E. F: Sobre chamas e cristais: a linguagem cotidiana, a linguagem científica e o ensino de ciências. In: CHASSOT, A. (Org). Ciência, ética e cultura na educação. São Leopoldo: Editora Unisinos, 1998. p. 99-118.

PARAISO, M.A: É possível um currículo fazer desejar? In: Paraíso, M.A(org): Pesquisas sobre currículos e culturas: temas, embates, problemas e possibilidades. - 1.ed - Curitiba: Editora CRV. 2010. 171p.

SANTOS, M. E.V: Que educação? (Tomo I). - Lisboa: Santos-Edu, 2005, $138 p$.

SANTOS, W.L.P.; MORTIMER, E.F. Uma análise de pressupostos teóricos da abordagem C-T-S (Ciência - Tecnologia - Sociedade) no contexto da educação brasileira. Ensaio - Pesquisa em Educação em Ciências, v. 2, n. 2, 2002.

TASSINARI, A. M. I. Escola indígena: novos horizontes teóricos, novas fronteiras de educação. pp. 44-69. In. SILVA, A. L.; FERREIRA, M. K.L. Antropologia, história e educação: a questão indígena e a escola. São Paulo: Global Editora e distribuidora Ltda. 2001.

VALADARES, J. M: O professor diante do espelho: reflexões sobre o conceito de professor-reflexivo. In: PIMENTA, Selma G; GHEDIN, E (org): Professor reflexivo no Brasil: gênese e crítica de um conceito. - São Paulo. Cortez, 2002.

VALADARES, J. M.; PEREIRA, V. M. Os desafios da interculturalidade, o currículo da educação indígena e a formação docente. In: PEREIRA; Maria Zuleide da Costa; ALBINO, Angela Cristina Alves; DANTAS; Veridiana. (Org.). Políticas de currículo e formação: desafios contemporâneos. João Pessoa: Editora da UFPB, 2015. p. 134-1471.

Recebido em: 06/06/2017

Aprovado em: 04/07/2017 